\title{
A Study of Transient Over-Fuelling During Heavy Knock in an Optical Spark Ignition (SI) Engine
}

Hassan Vafamehr, Alasdair Cairns, Hazhir Ebne-Abbasi

Faculty of Engineering, University of Nottingham, Nottingham, NG7 2RD

Hassan.vafamehr@nottingham.ac.uk-alasdair.cairns@nottingham.ac.uk-abbasi.hazhir@gmail.com

\begin{abstract}
The work was concerned with improving understanding of the effects of transient over-fuelling during heavy knocking combustion in modern spark ignition engines. The single cylinder engine employed included full bore overhead optical access capable of withstanding unusually high incylinder pressures. Heavy knock was deliberately induced under moderate loads using inlet air heating and a primary reference fuel blend of reduced octane rating. High-speed chemiluminescence imaging and simultaneous in-cylinder pressure data measurement were used to evaluate the combustion events. Under normal operation the engine was operated under port fuel injection with a stoichiometric air-fuel mixture. Multiple centred auto-ignition events were regularly observed, with knock intensities of up to $~ 30$ bar. Additional excess fuel was then introduced directly into the end-gas in short transient bursts. As the mass of excess fuel was progressively increased a trade-off was apparent, with knock intensity first increasing by up to $65 \%$ before lower unburned gas temperatures suppressed knock under extremely rich conditions. This trade-off is not usually observed during conventional low intensity knock suppression via over-fuelling and has been associated with the competing effects of reducing auto-ignition delay time and charge cooling/ratio of specific heats. Overall, the results demonstrate the risks in employing excess fuel to suppress knock deep within a heavy knocking combustion regime (potentially including a SuperKnock regime).
\end{abstract}


KEYWORDS: Optical, Auto-Ignition, Developing Detonation, Downsizing, Knock, Super-Knock

\section{INTRODUCTION}

Within Europe, passenger car carbon dioxide $\left(\mathrm{CO}_{2}\right)$ emissions targets have largely been met through increased diesel sales, which have now approach saturated levels [1]. In the short-tomedium term it will be necessary to improve the fuel consumption of the gasoline engine and in the longer term source sustainable alternatives to crude oil. Substitutes such as electric and hydrogen fuel cell vehicles, hybrid vehicles, and biofuels (e.g. bioethanol and biodiesel) are among the alternatives being investigated. However, significant challenges remain regarding the sustainability of such technologies to meet global demand. For electric vehicles, relatively low energy and power densities and the high cost of the battery remain the main barrier [2]. For biofuels, two main challenges need to be addressed. The first is to refute environmental harm caused by the combustion of carbon-based fossil fuels whereas the second is energy security and sustainability [3].

One of the most promising methods from improving gasoline engine efficiency is engine downsizing. The basic principle is to reduce the capacity of the engine and hence enforce a large proportion of operation to higher loads. As a result of the under wider open throttle conditions the pumping losses are reduced for a given road load requirement. In order to maintain adequate vehicle acceleration and top speed, the smaller engine must be pressure-charged and still produce acceptable transient response. Overall, for a large family-sized saloon car, it has previously been demonstrated that halving total engine capacity from a V6 2.4 litre to a three-cylinder 1.2 litre unit can reduce fuel consumption by up to $\sim 25 \%$ with vehicle performance maintained [4].

Such downsizing clearly yields significant part-load fuel consumption benefits, but significant challenges remain including problematic combustion. Downsizings (and “downspeeding”) enforce a considerable proportion of "real world" operation to the low speed high load regime. Under such conditions the increased energy density of a highly pressure charged mixture leads to an increased 
tendency for the fuel and air to auto-ignite. The problem of auto-ignition is almost as old as the internal combustion engine itself and ultimately caps peak thermal efficiency, being commonly avoided by selecting a lower compression ratio, retarding the spark timing and/or introducing excess fuel. Such auto-ignition has been considered to be the result of exothermic centres, or "hot spots", leading to auto-ignition of the unburned charge ahead of the developing flame [5,6]; socalled end-gas auto-ignition. However, recent aggressively downsized research engines of very high specific output have additionally experienced pre-ignition combustion at low engine speeds and high loads ( $>20$ bar BMEP). Previously pre-ignition was most commonly associated with higher engine speeds, when the components within the combustion chamber are typically at their hottest. Hence such pre-ignition was at first unexpected, arising below the auto-ignition temperature of the charge and occurring in a highly sporadic manner in short violent bursts in an "on-off" pattern, with sometimes tens of thousands of cycles in-between events [7].

This phenomenon sometimes referred to as Low Speed Pre-Ignition (LSPI) and "Super-Knock", has been associated with low-to-moderate thermal gradients within the unburned charge leading to developing detonation events. Ultimately, this may produce multiple high frequency and intensity pressure waves within the cylinder that may interact and ultimately destroy the engine $[8,9]$. Researchers at Leeds and Shell [10] have recently postulated that such Super-Knock events originate from a resonance between acoustic waves emitted by an auto-igniting hot spot and a reaction wave that propagates along negative temperature gradients in the fuel-air charge. The theory is based upon the assumption that the temperature gradient extends smoothly over sufficient length across the turbulent flow field. Subsequently, localised detonations may develop which are then able to violently ignite the remaining unburned charge in timescales of less than a millisecond. Ultimately, this can lead to catastrophic mechanical engine failure. In existing downsized engines the phenomenon is avoided by running fuel rich, where the charge cooling properties of the excess fuel reduce pre-ignition tendency at the expense of poor fuel consumption and vastly increased tailpipe emissions (given the three-way catalyst is no longer effective). Such operation is clearly not 
sustainable, particularly in light of the real world driving cycles currently being proposed with the EU and elsewhere to cover a wider area of engine operation in the future. Hence the current work was concerned with evaluation of the transient effects of intra-cycle overfuelling as a potential method to allow improved efficiency in future real world cycles. In addition the work was intended to demonstrate the trade-off between increased charge cooling and reducing ignition delay when suppressing knock by varying rich conditions in a real engine.

The currently reported work was therefore concerned with evaluating the effects of excess fuel when introduced under existing heavy knock conditions as might be experienced sporadically in modern automotive gasoline engines.

\section{Experimental Setup}

\subsection{Optical Engine}

The experiments were undertaken using a customized single cylinder research engine with a unique optical arrangement. The bottom-end was based on a commercial Lister-Petter TS1 including fullbore overhead access and a semi-traditional poppet-valve valvetrain. Using a special window mounting the engine has been designed to withstand continuous peak in-cylinder pressures of up to $150 \mathrm{bar}$. Otherwise the unit incorporated a flat piston crown, two inlet ports, and originally was designed with two exhaust ports. To increase trapped residuals and help invoke knock one of the exhaust valves was deactivated as previously adopted by Dingle et al. [11] and illustrated in Figure 1. The recessed side mounted poppet valves helped achieve valve overlap without piston clash and maintain a compression ratio of 8.4:1 [11].

The engine was coupled to an eddy-current dynamometer with a maximum power absorption/supply of 10kW. Port fuelling was controlled via a Bosch EV6 PFI fuel injector regulated to 3 bar rail pressure. The PFI injector mounted in the intake port and had a 2-hole pattern 
forming a dual plume spray pattern targeted towards the intake valves. In addition, a production

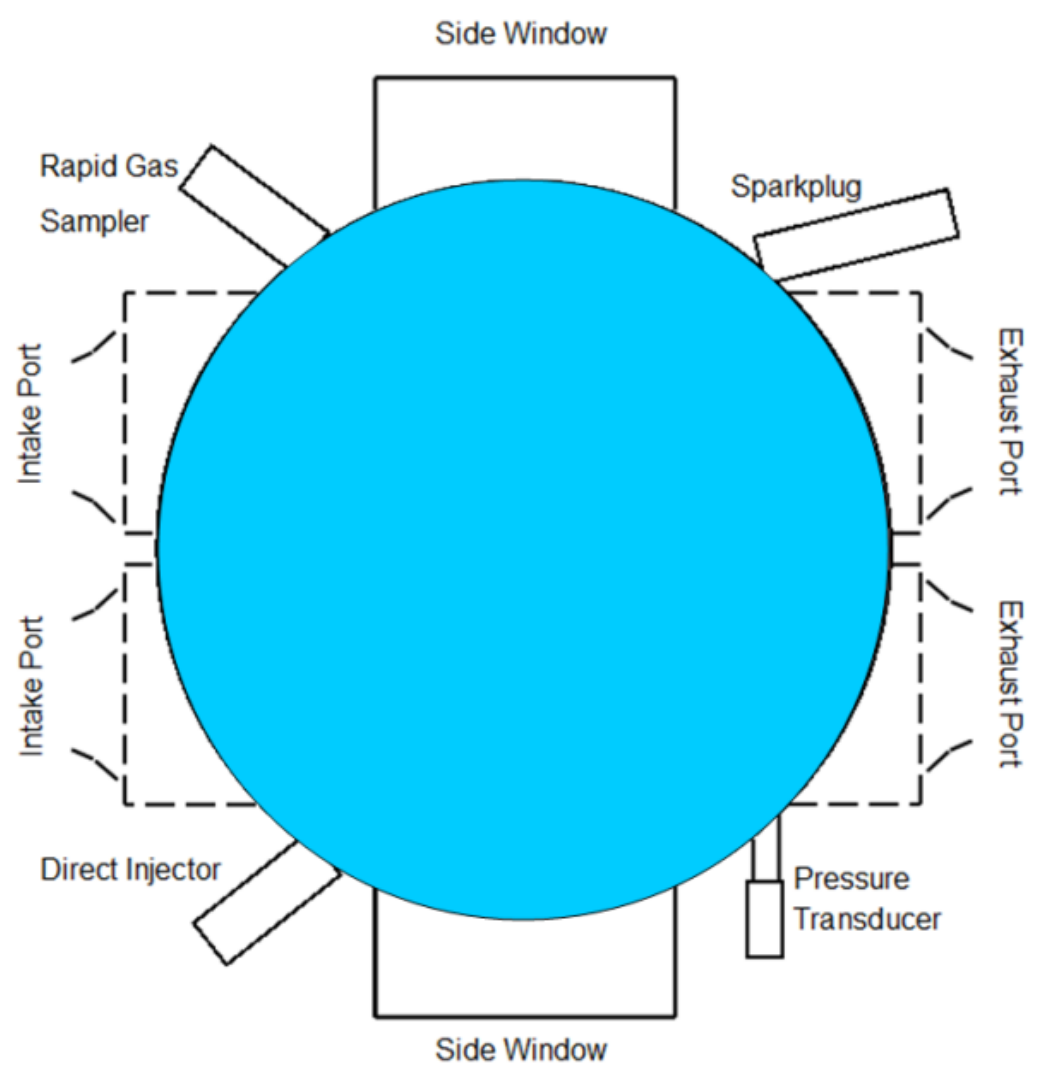

Figure 1: Overhead view of the full-bore window

multi-hole direct fuel injector was positioned in the side of the head as indicated in Figure 1. The rail pressures of the PFI and DI fuel systems were set to 3 bar and 65 bar gauge respectively. The injection timing for port fuel injection was fixed (with an end of injection at $400^{\circ} \mathrm{bTDC}$ firing) while the timing of the DI was varied. Throughout the tests the engine was fuelled using a "PRF75" blend (75\% isooctane, $25 \% \mathrm{n}$-heptane), with high purity isooctane and n-heptane obtained from a chemical supplier and blended on a volumetric basis. The chemical properties of the reference fuels are provided in Appendix A. The ignition system comprised of an NGK ER9EH 8mm spark plug connected to a Bosch P100T ignition coil. The full experimental setup is shown schematically in Appendix B. 


\begin{tabular}{|l|c|}
\hline Parameter (unit) & Value \\
\hline Number of Cylinders & 1 \\
\hline Compression Ratio & $8.4: 1$ \\
\hline Stroke (mm) & 89 \\
\hline Bore (mm) & 95 \\
\hline Displacement (cc) & 631 \\
\hline Con-rod Length (mm) & 165.16 \\
\hline Valve Lift (mm) & 5 \\
\hline Inlet Valve Openings/Closing ( ${ }^{\circ}$ bTDC in degree) & $375 / 145$ \\
\hline Exhaust Valve opening/Closing ( ${ }^{\circ}$ aTDC in degree) & $120 / 350$ \\
\hline
\end{tabular}

Table 1 Key Engine Geometry

\subsection{Thermodynamic Analysis}

A modern non-cooled AVL GH14DK pressure transducer was fitted in the cylinder head, with the face of the transducer mounted flush with the combustion chamber walls. The intake plenum pressure was also measured using a GEMS 1200 series CVD sensor. Both of these were recorded at four samples per crank angle degree via a digital shaft encoder, attached to the intake camshaft, and a Labview high-speed USB data-logging card. The engine operating temperatures were measured via a separate lower-speed card at $1 \mathrm{~Hz}$. Since the research engine was air-cooled, the cylinder head and liner temperatures were strictly monitored throughout the tests with two large stationary electric air fans positioned around the engine for improved temperature control. Cylinder head temperature measurement was undertaken at two locations: a) the DI injector tip and b) the exhaust valve bridge. The measurements obtained by both cards were collated and processed using an in-house MATLAB based system. The well-known Rassweiler and Withrow method [12] was used to determine the Mass Fraction Burned (MFB), which was considered adequate for the qualitative analysis intended. Thermodynamic results were averaged over 300 cycles but obtained in 100 cycle batches to minimise metal temperature variation effects in the air cooled unit. The average knock intensity was computed by filtering the raw pressure signal and calculating the average peak value over the full 300 cycles. 


\subsection{Engine Test Procedure}

A fixed reference point was obtained by running the engine under normal non-knocking part-load operation until the cylinder head metal temperature reached $88^{\circ} \mathrm{C}$. At this temperature knock was instantaneously induced by advancing the spark timing. After capturing the data, the engine was stopped, allowed to cool and the process repeated. This process kept the measured wall temperatures within a small range $\left(<5^{\circ} \mathrm{C}\right.$ peak-to-peak variation), which was considered necessary when considering knock in a qualitative manner with an engine setup lacking water cooling in the head. In a similar manner to knock intensity calculations, the thermodynamic results were averaged over three sets of 100 cycles for each test condition. Table 2 below shows the engine test conditions. The sump oil temperature remained moderately low but fixed throughout testing $\left(\sim 40^{\circ} \mathrm{C}\right)$.

\begin{tabular}{|l|c|}
\hline Parameter (unit) & Value \\
\hline Engine Speed $(\mathrm{RPM})$ & $1200 \pm 5$ \\
\hline Relative AFR $(\lambda)($ PFI Only) & $1 \pm 0.01$ \\
\hline COV of IMEP $(\%)($ PFI Only) & 5 \\
\hline Inlet Pressure $($ bar) & $0.9 \pm 0.02$ \\
\hline Inlet Air Temperature $\left({ }^{\circ} \mathrm{C}\right)$ & $66 \pm 2$ \\
\hline Exhaust Bridge Temperature $\left({ }^{\circ} \mathrm{C}\right)$ & $130 \pm 2$ \\
\hline DI Tip Temperature $\left({ }^{\circ} \mathrm{C}\right)$ & $102 \pm 4$ \\
\hline Head Temperature $\left({ }^{\circ} \mathrm{C}\right)$ & $88 \pm 1$ \\
\hline
\end{tabular}

Table 2 Engine Test Conditions

\section{Transient Direct Fuel Injection Results}

Set out in Figure 2 are the cycle-by-cycle values of average knock intensity with and without additional direct fuel injection, with the Direct Injection Start of Injection (DI SOI) timing set to $60^{\circ} \mathrm{bTDC}$ firing and the DI pulse width set to $7 \mathrm{~ms}$. Under these conditions the overall relative airto-fuel ratio increased from $\lambda=1.0$ to $\lambda=0.66$. The dashed line superimposed shows the activation signal sent to the DI injector. The average values of knock intensity (KI) before and after direct 
injection were 7.7 bar and 0.48 bar respectively. It can be seen that that knock was largely suppressed and returned to similar levels when the fast over-fuelling was deactivated after $\sim 30$ cycles albeit marginally lower in magnitude (KI $\sim 6.3 \mathrm{bar}$ ) associated with the lower peak gas temperatures during non-knocking combustion and differences in wall heat transfer. The differences in the in-cylinder pressure development are more apparent when observing the waterfall plot in Figure 3, which shows a cropped selection of cycles immediately before, during and after the over-fuelling event. Overall the result confirmed the experimental setup, with the elimination of knock associated with the previously well reported charge cooling and ratio of specific heat effects of a relatively high amount of excess fuel introduced within the cylinder $[13,14]$. However, such a result cannot provide insight into transient fuelling events experienced in real engines under sudden heavy knocking as is the case with low speed pre-ignition and Super-Knock.

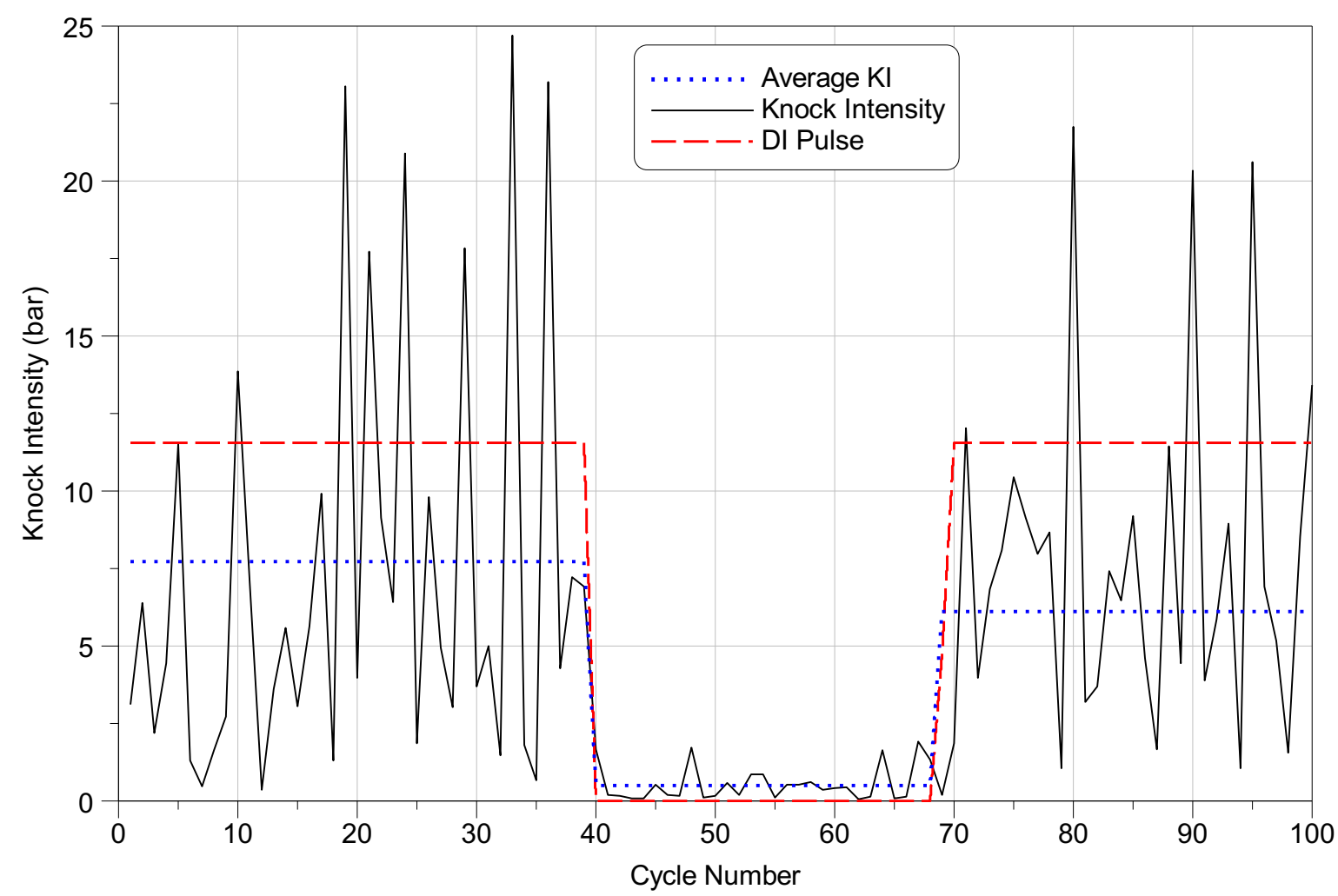

Figure 2: Individual cycle average knock intensity versus engine cycle number before, during and after a transient over-fuelling event 


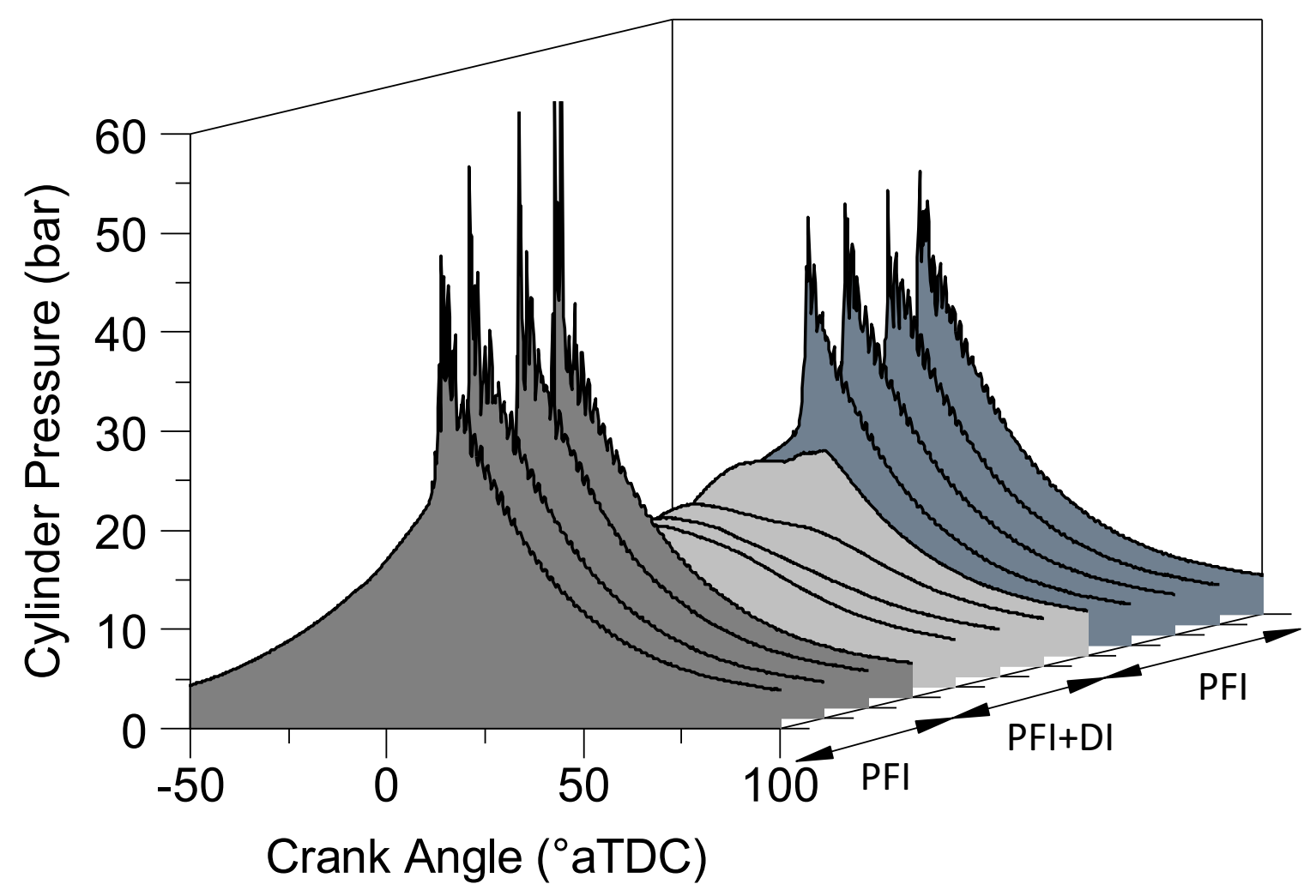

Figure 3 Waterfall plot showing the differences in the in-cylinder pressure development before, during and after additional direct fuel injection

\section{Start of Injection Timing Sweep}

A DI SOI timing sweep was undertaken to establish response to varying fuel stratification, as might be experienced during real transient engine operation and/or advanced knock control in modern DI engines. Typically, after the exhaust valve closes, the earlier the injection timing the more homogeneous the fuel/air equivalent ratio field. However, it is also important to note that the mixture formation homogeneity, bulk fluid motion and turbulence intensity during the compression stroke can be strongly affected by the piston and the direct injection.

Throughout the sweep the DI fuel pressure was left fixed at 65 bar. This left two variables; injection timing and additional fuel mass (injection pulse width). In initial work, the pulse width was fixed to a relatively high value of $7 \mathrm{~ms}$ (estimated to be an upper limit given the above result) and the SOI 
timing swept from $120^{\circ}$ to $20^{\circ} \mathrm{bTDC}$ firing in intervals of $5^{\circ}$ crank. The results are set out in Figure 4, where the solid black dots denote the value of average KI measured immediately prior to each DI activation in PFI-only mode, included to show the consistency of the baseline knocking cases. The stars denote the average KI when the direct injection was activated. When the direct injection was advanced to $80^{\circ}$ bTDC or earlier the knock was appropriately suppressed, with sufficient time remaining for the additional fuel mass to mix into the end gas region. With later injection timings the knock intensity progressively increased, with average KI values as high as $\sim 3$ bar but with some individual cycles exhibiting knock intensities of up to 12 bar at the latest injection timings studied. The excess fuel suppresses the knock via two well known mechanisms. Firstly, the charge cooling effect associated with evaporation of the fuel and secondly the reduced ratio of specific heats under richer conditions leading to lower end-gas temperatures after compression, as previously demonstrated in a real multi-cylinder DI engine [13]. However, it is important to note that autoignition delay times reduce under rich conditions, which becomes more important when using excess fuel under severe knocking conditions as discussed in more detail below.

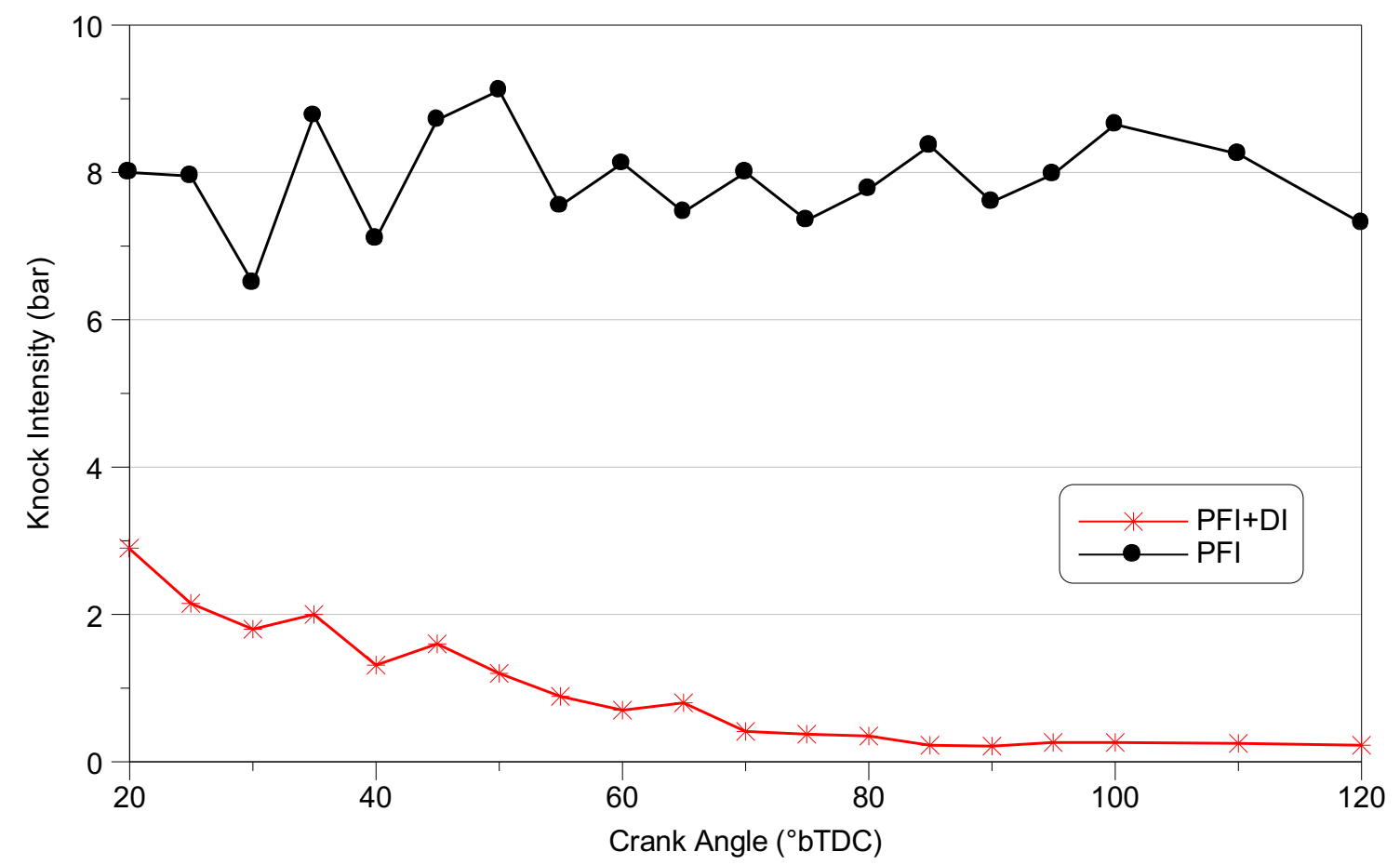


Shown in Figure 5 are key thermodynamic values during the DI timing sweep. It should be acknowledged that the engine was operating at the stability limit under PFI only, due to the running conditions necessary to invoke heavy knock. As the DI was introduced it can be seen that the stability fell below the COV of IMEP threshold; associated with advanced and faster combustion. In turn, the output of the engine increased. Clearly some stratification in the DI fuel was favorable to the mass burning rate and knock suppression, presumably due to preferential local conditions in the end-gas leading to lower temperature and/or prolonged auto-ignition delay. These observations appear to be in good agreement with those of Wang et al. [15], who employed split (double) direct injection to suppress Super-Knock in a modern downsized DI engine. However, some caution is required in this comparison as the exact mechanisms of Super-Knock suppression (i.e. stratification, reduced wall wetting) are unknown in each case. In future work it is intended to study such effects under elevated injection pressures with different fuels. 

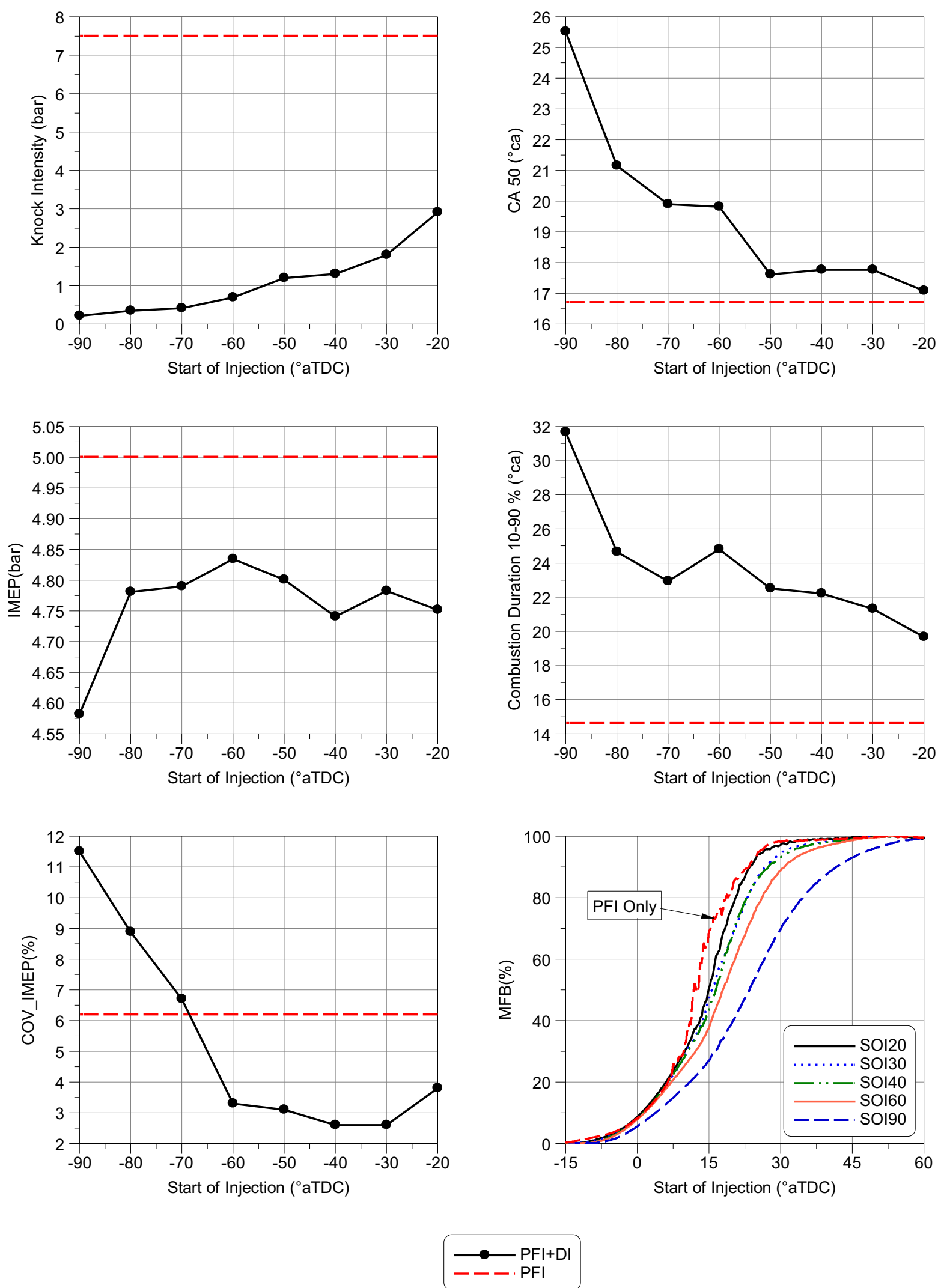

Figure 5: Thermodynamic operating parameters during the SOI timing sweep 


\subsection{Direct Fuel Injection Duration Sweep}

A direct fuel injection duration sweep was undertaken to establish the response to progressively increasing fuel mass, as might be experienced during real transient engine operation with knock control. During the experiment the SOI timing was left fixed at $60^{\circ} \mathrm{bTDC}$ and the fuel rail pressure set to 65 bar. Set out in Figure 6 are the values of average knock intensity. Shown in Figure 7 are the corresponding measured values of relative air-to-fuel ratio (obtained via a wide band sensor fitted in the exhaust). Although the charge cooling and ratio of specific heat effects are well known, in this study it can be seen that by adding small amount of fuel using DI injector, knock intensity increased by $\sim 65 \%$ at $1.5 \mathrm{~ms}$ compared to the baseline PFI-only case. It should also be noted that the load reduced marginally throughout the sweep, steadily falling from 5.1bar (PFI-only) to 4.7bar IMEP at the richest condition. The increasing knock intensity has been associated with reducing auto-ignition delay times under richer conditions on the onset of the graph,

This observation was validated by reviewing the auto-ignition delay times for the two components of the fuels, with an example set out in Figure 8. This figure has been directly reproduced from recent simulation work by Stapf and Reis [16], where the solid lines denote their own predictions and the data points experimental shock tube measurements made elsewhere $[17,18]$. The predictions were based upon a simple Livengood-Wu integral model linked to a zero-dimensional engine code fed with experimental in-cylinder pressure. For both primary reference fuel components it can be seen that there is good agreement between the simulated and experimental results and that the autoignition delay time reduces under richer operating conditions (albeit notably more so in the case of n-heptane). 


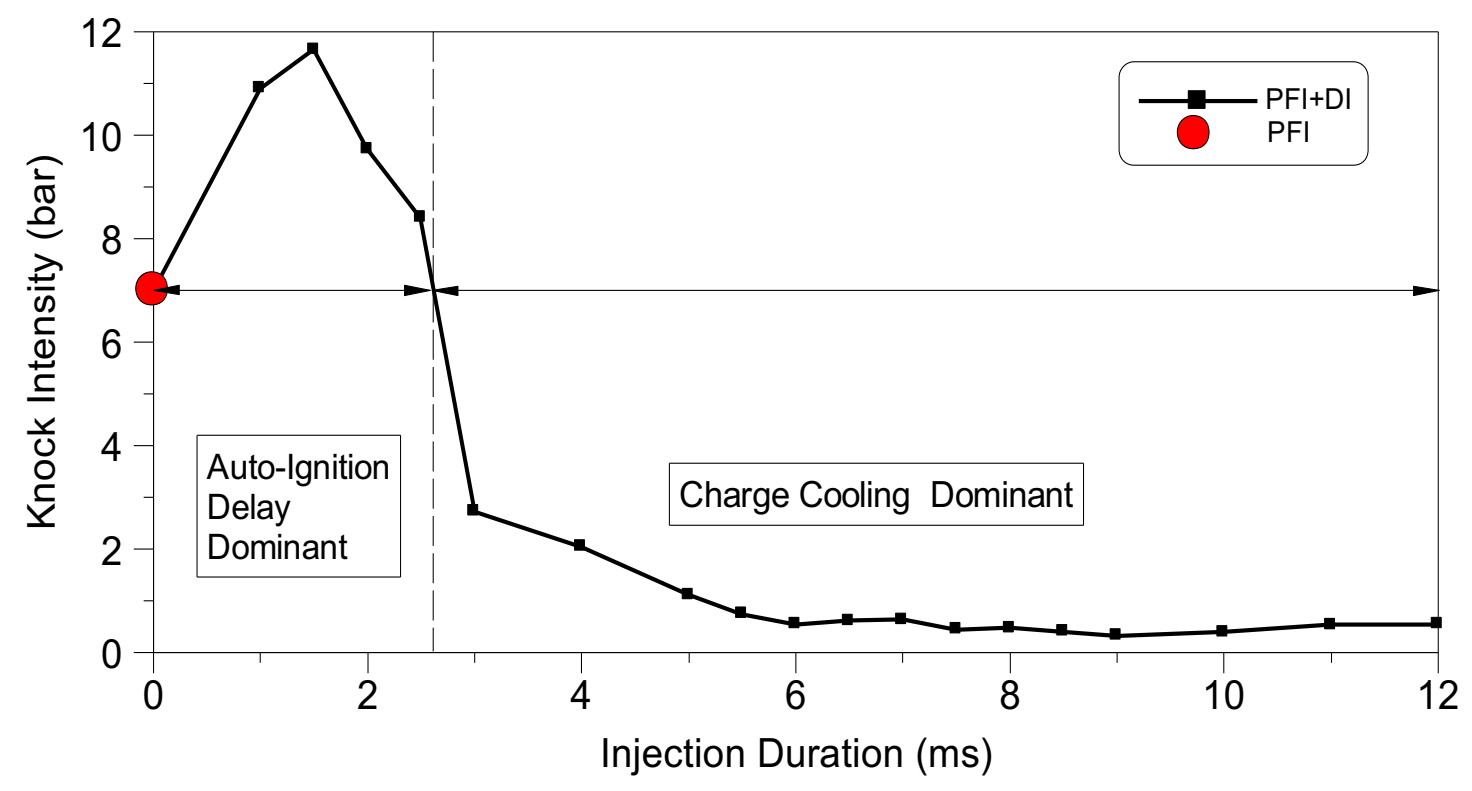

Figure 6: Average knock intensity versus direct fuel injection duration

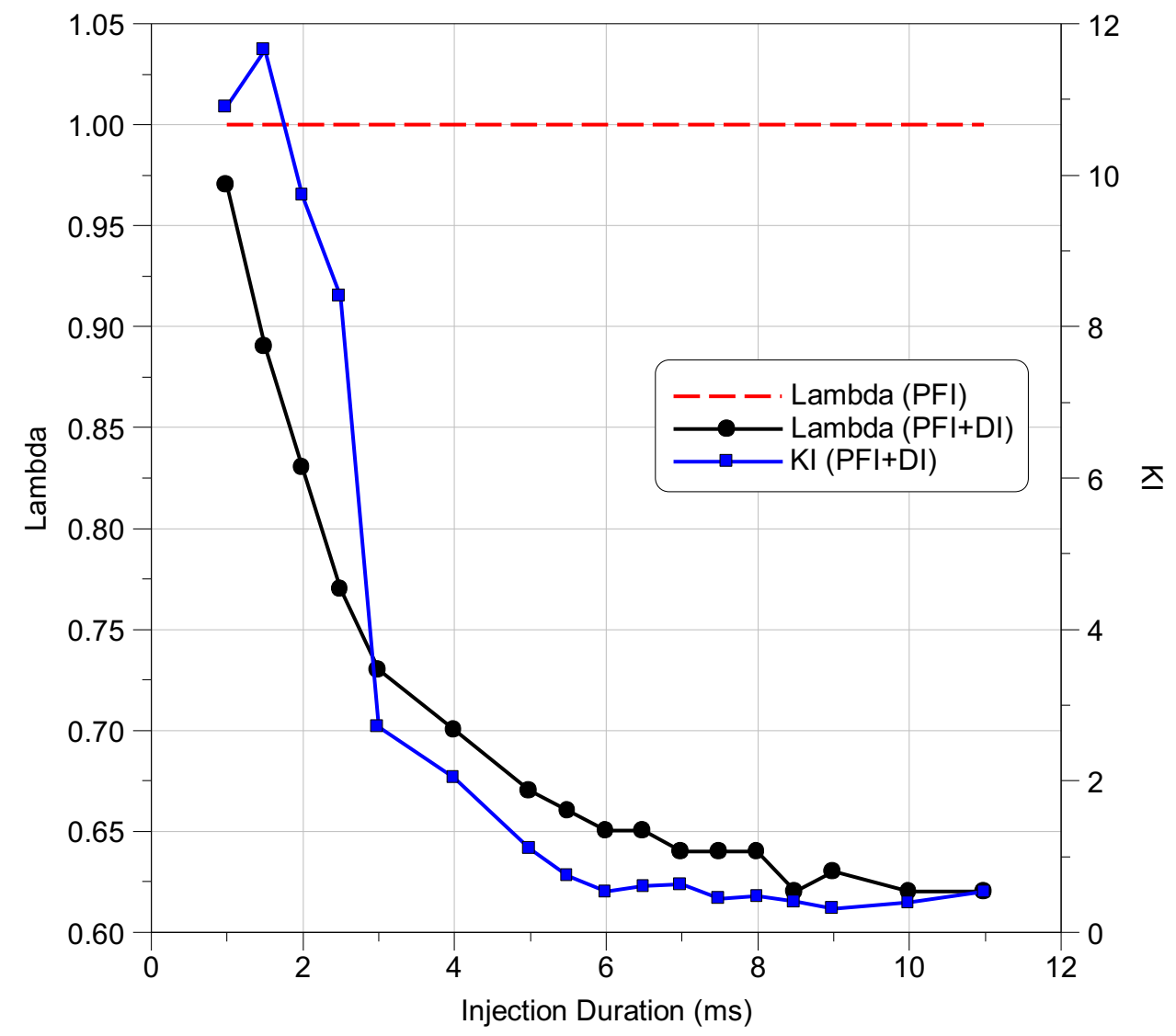

Figure 7: Injection Duration Sweep for different cycles during the PFI + DI with the average superimposed 


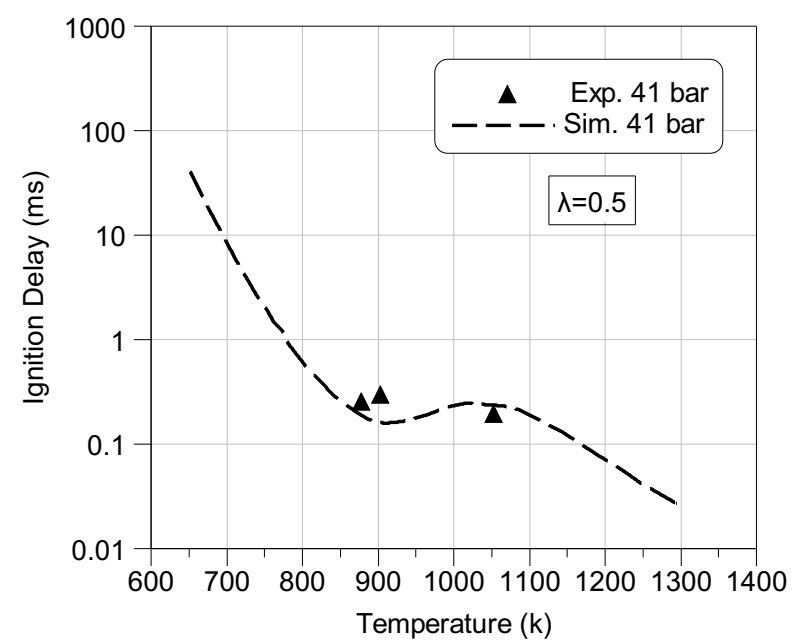

(a)

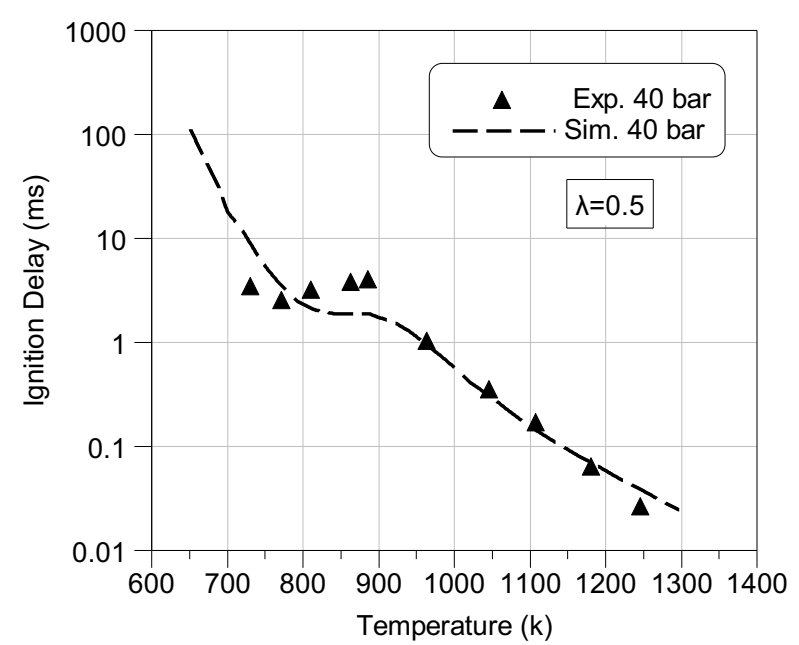

(c)

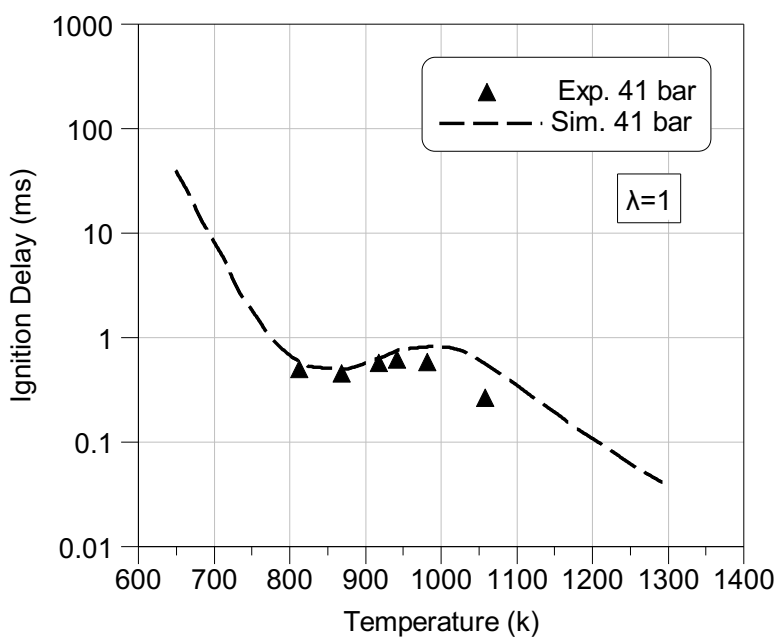

(b)

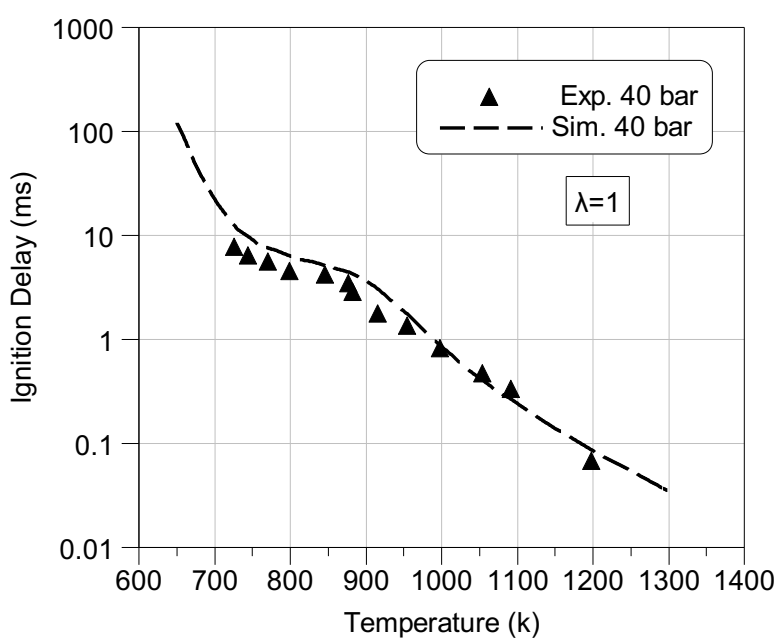

(d)

Figure 8: Predictions and measurements of auto-ignition delay versus gas temperature for isooctane under a) rich and b) stoichiometric conditions compared to equivalent values for nheptane (c, d). Reproduced from [16]. 


\section{Optical Analysis}

Shown in Figure 9 are flame images from three cycles selected to show "typical" events under varied start of injection timings for the transient DI events. Each horizontal strip denotes a different cycle and SOI setting, as marked on the figure. As before, the fuel injection pulse width and DI rail pressure remained fixed at $7 \mathrm{~ms}$ and 65 bar respectively. The bright yellow-ish light omission denotes local sooty combustion in the end-gas region, with the phenonenon exacerbated as the DI timing was retarded. Set out in Figure 10 are corresponding flame image strips showing the "optimum" PFI+DI case versus PFI-only (with the flame images shown in the same orientation as Figure 9). Based on the previous results the optimum direct injection timing was considered to be $60^{\circ}$ bTDC. Shown in Figure 11 is the single frame at $22.8^{\circ}$ aTDC where multiple-centred knock initiation sites were captured in the baseline PFI case. The contrast in this frame has been manipulated after imaging for improved clarity. Such multiple centres were regularly noted under heavy knocking conditions, in good agreement with prior developing detonation theory [19-21]. Also Male [22] noted that the explosive detonation reaction may be composed of many individual detonation reactions. Furthermore the end zone becomes sufficiently conditioned or sensitive that many seprate areas become centres for starting detonation reaction. Under the rich PFI+DI conditions, in Figure 10 the flame can be seen to propagate rapidly downward toward the direct injector, with an apparent peninsular of flame growth in the bottom left-hand area of the bore potentially associated with favourable local mixutre strength. This phenomenon was regularly observed under these optimum settings. Overall, increased chemiluminescence was observed throughout the PFI+DI flame propagation event, indicating some of the DI fuel had reached the region the spark plug region of the bore due to the (relatively) earlier direct injection timing. 

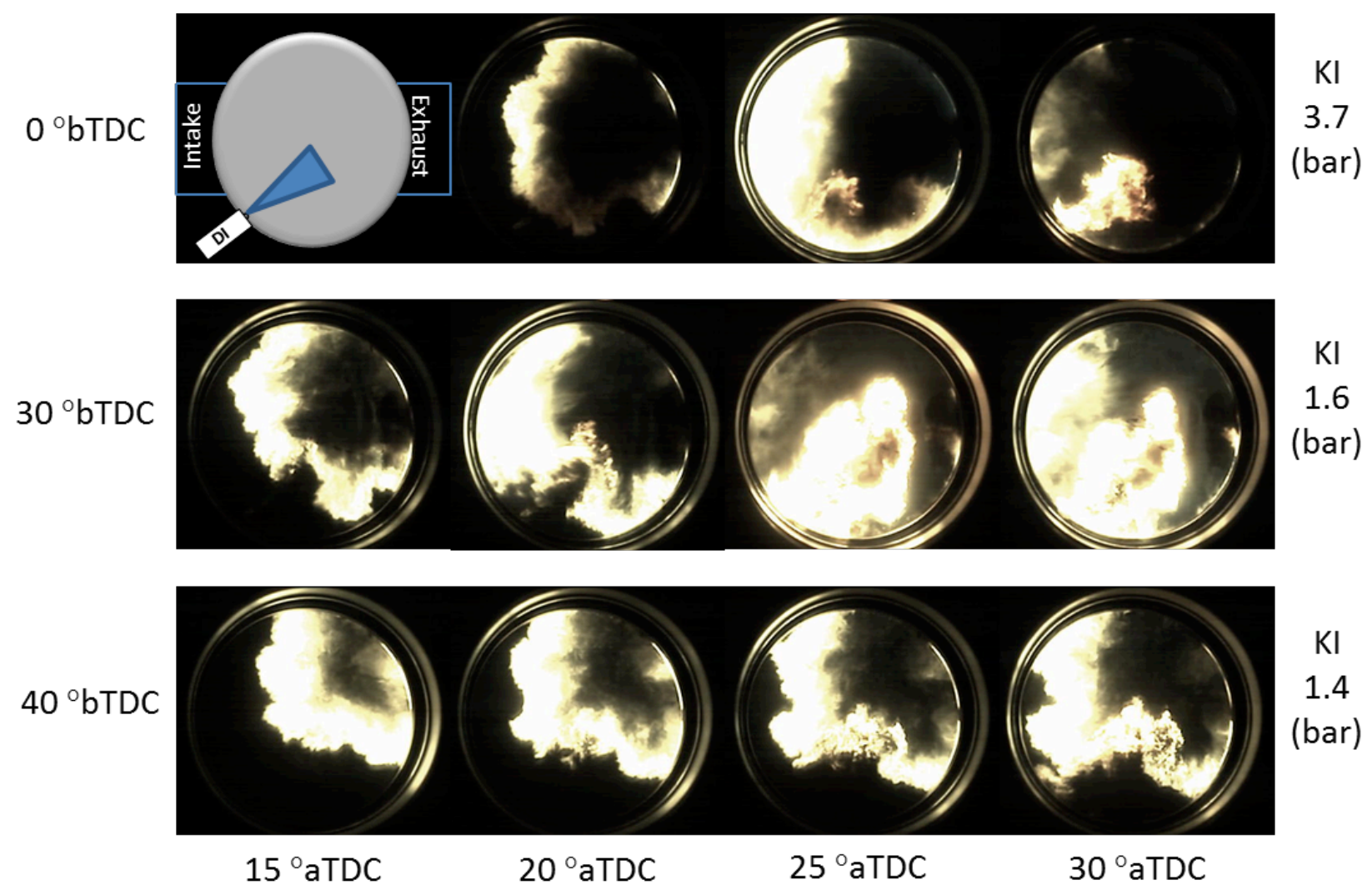

Figure 9: Flame images under varied direct injection SOI timings. Each horizontal strip shows a different cycle obtained at different DI SOI timing (marked on the left). 


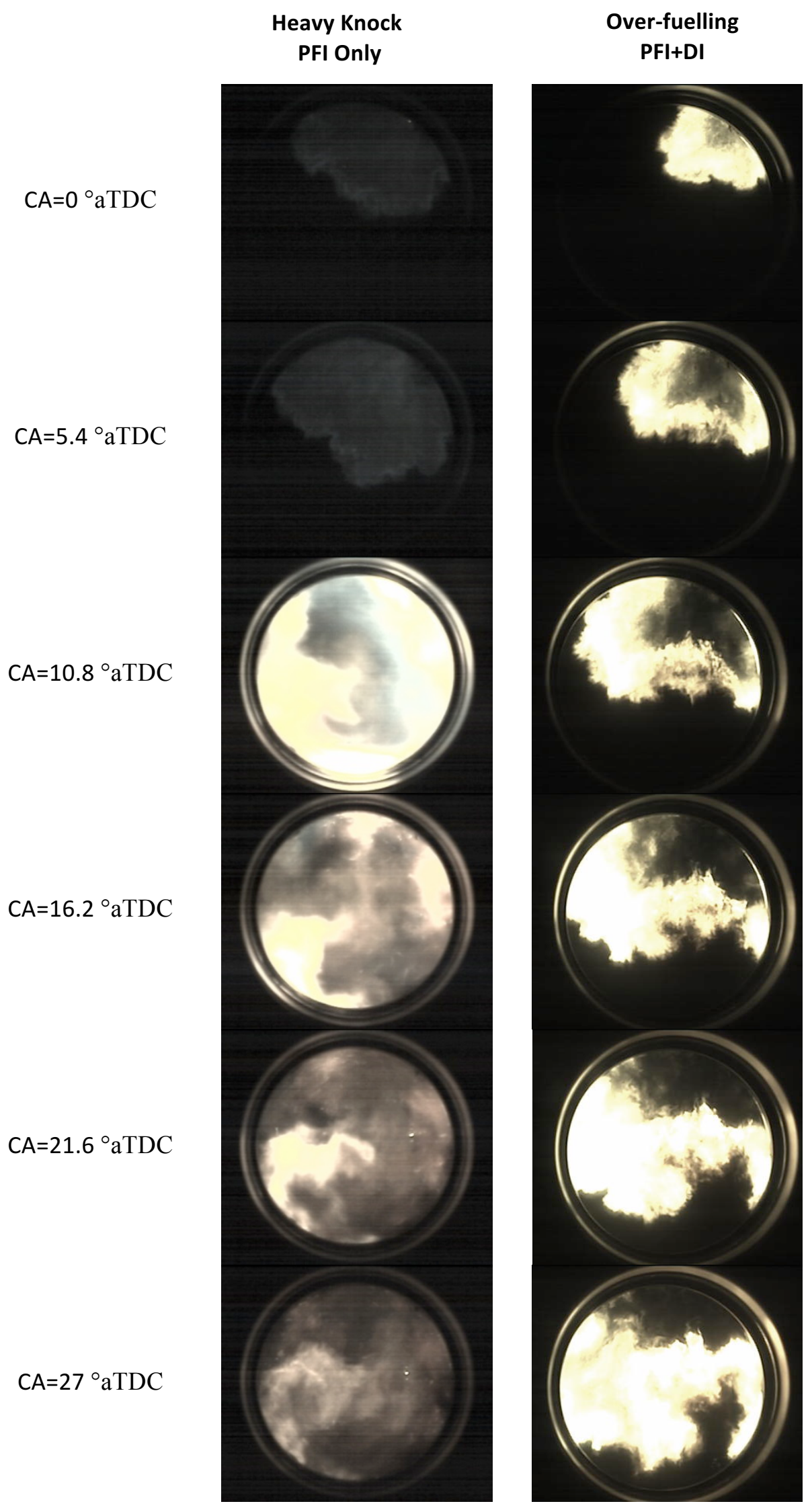

Figure 10: A comparison of a typical baseline heavy knocking cycle versus a typical "optimum" over-fuelling cycle 


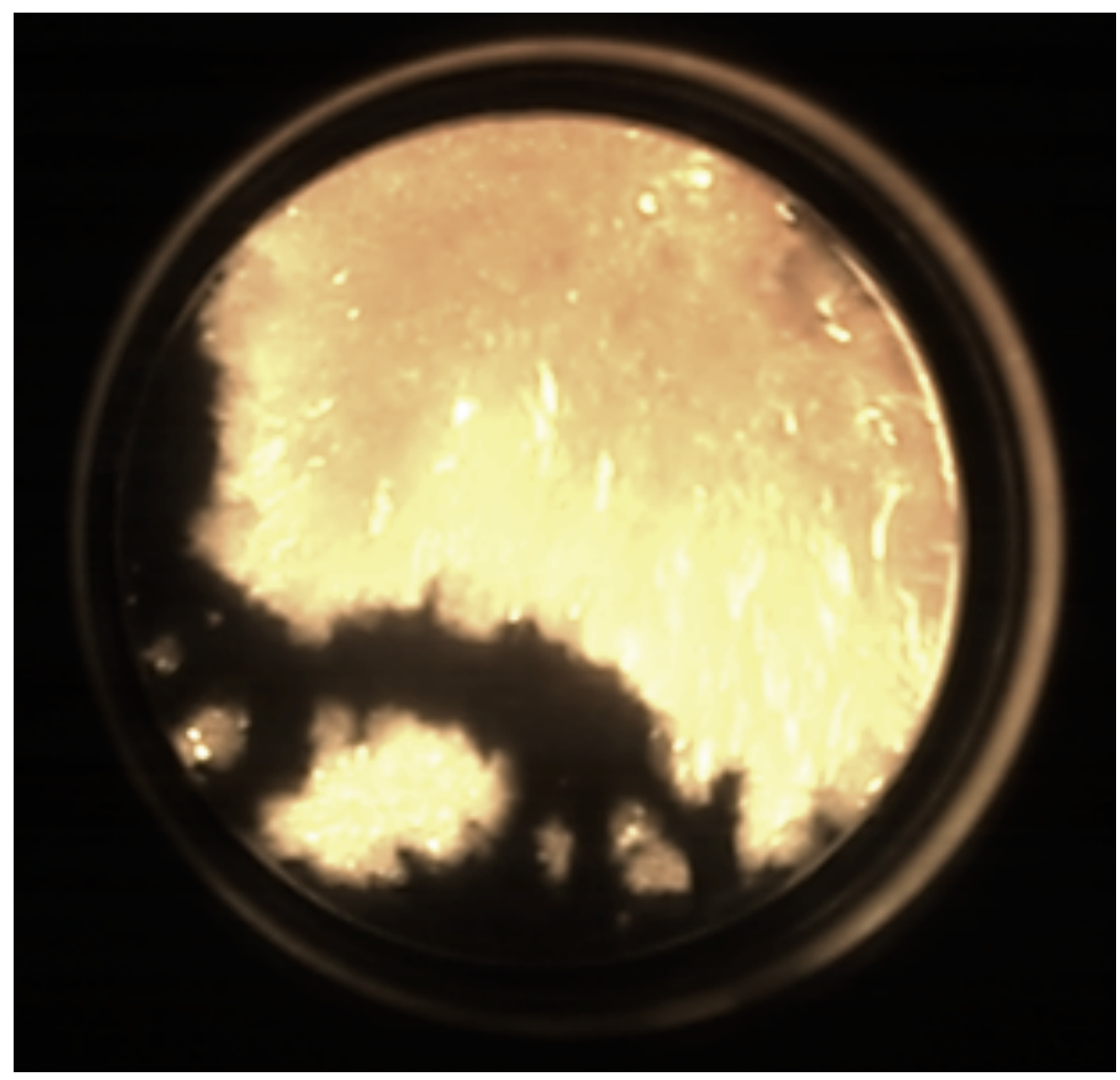

Figure 11: Blown-up intensified view of the multiple auto-ignition initiation sites observed during the baseline heavy knock cycle shown in Figure 10

\section{Visible Oscillations Following End-Gas Auto-Ignition}

In-Cylinder pressure oscilation under knoking condition is a familiar topic in engine research field [23-26]. In recent work by Kawahara and Tomita [27], auto-ignition and pressure wave during knocking was visualised. They have stated strong pressure wave oscillations induced by the initial auto-ignition could be visualised using a video camera with the ultra high speed camera. Also in other research it has been noted that the mass moved back and forth across the cylinder [22].

During the heavy knocking cycles an oscillation of the burned gasses was visible within the combustion chamber. While the oscillations were clear when the images were viewed as a video, they were not easily visible when viewed as a printed image sequence. Therefore, a method was devised to quantify and track the oscillations using a Matlab script to locate the intensity weighted centroid of the burned gas region. The concept of this measurement was to reduce each combustion image into a single point that represented the average point of light emission from the combustion chamber as shown in figure 12. 


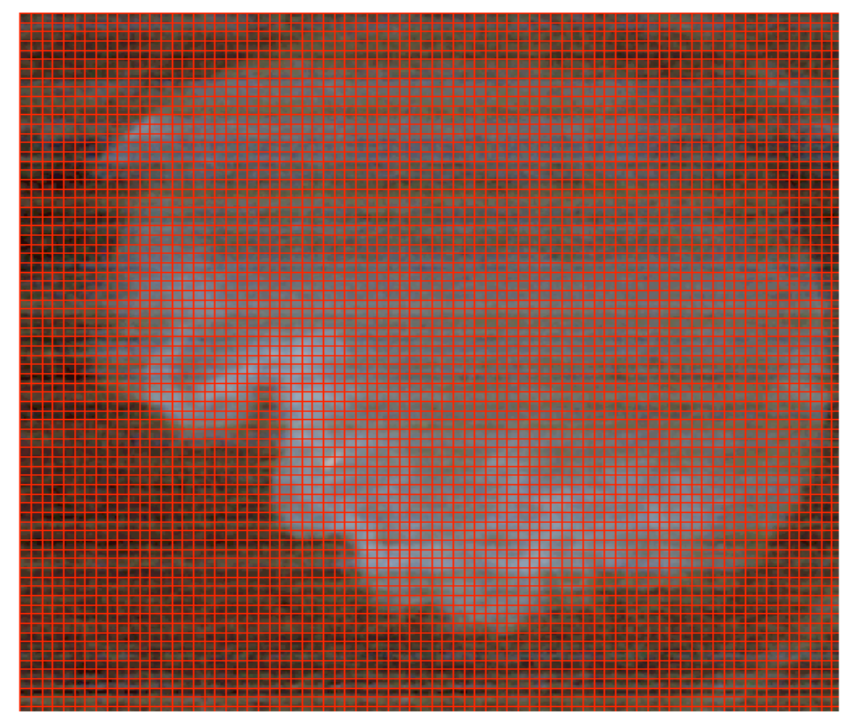

Figure 12: Combustion intensity weighted centroid (circled cross) of the imaged flame (left), Example output from produced mesh in Matlab code (right)

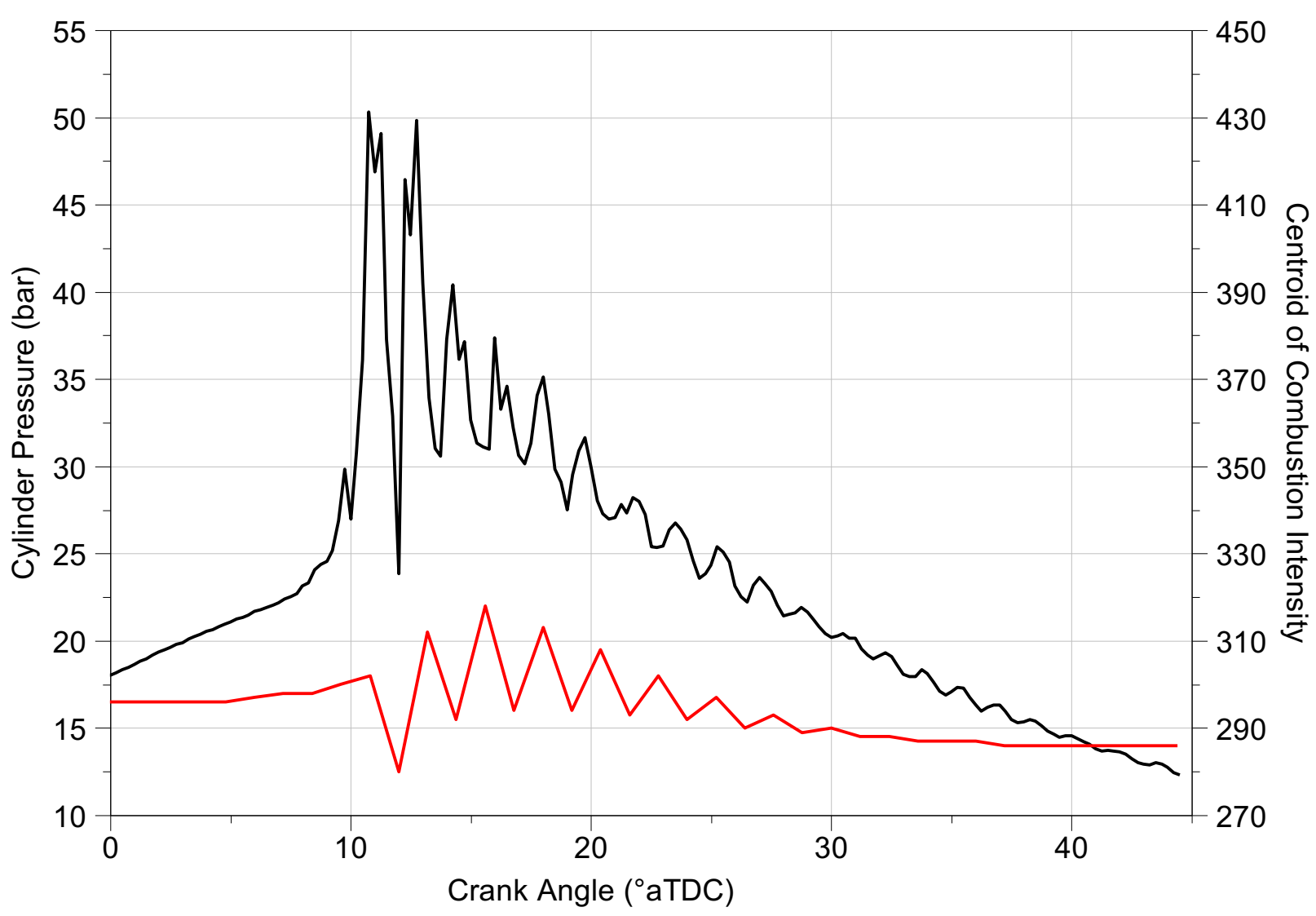

Figure 13: Centroid of combustion intensity and cylinder pressure against crank angle for knocking cycle

In the video it could be seen that the oscillations travelled approximately from left to right (between the intake and exhaust valves) about the x-axis of the image. Therefore the $\mathrm{x}$-axis location of the centroid was plotted against crank angle as shown in figure 13. From the far left of the graph 
(between 0 and $\sim 11^{\circ} \mathrm{aTDC}$ ) it can be seen that there was a steady displacement of the centroid as the location was dominated by the development of the flame across the combustion chamber. At approximately $11^{\circ}$ aTDC there was a sudden shift in the centroid location as the end-gas was rapidly consumed by auto-ignition. Following this event the burned gas region encompassed the entire combustion chamber and the only factor affecting the intensity weighted centroid was the combustion intensity distribution of the burned gas region. At this point ( $\left.11^{\circ} \mathrm{aTDC}\right)$ the oscillations within the combustion chamber begin and are clear from the displacement of the centroid. By comparing the centroid location to the cylinder pressure (figure 13) there was a clear correlation between the two. However, it is thought likely that the oscillations in pressure only become visible at extremely high values of $\mathrm{KI}$. 


\section{CONCLUSIONS}

The work involved study of transient over-fuelling using additional direct fuel injection during heavy knocking PFI engine conditions. It was observed that directly injecting a small-to-moderate additional mass of fuel would exacerbate knock, with reducing auto-ignition delay time leading to higher peak in-cylinder pressures and knock intensities elevated by $\sim 65 \%$. As the additional mass of directly injected excess fuel was further increased the effects of charge cooling and reducing ratio of specific heats began to dominate and ultimately eliminated knock albeit requiring extremely rich conditions. It was also apparent that some stratification in the DI fuel was favorable to burning rate and knock suppression, associated with favourable local conditions in the end gas prior to the onset of auto-ignition. Full bore chemiluminescence imaging confirmed multiple centred auto-ignition sites and the need to balance the degree of pre-mixing of the excess fuel within the main charge, with increased light emission noted across the bore under the "optimum" DI conditions.

Overall, the results highlight the potential risks in transient over-fuelling under heavy knocking conditions, where an unexpected violent knock event (e.g. Super-Knock) might be exacerbated by the presence of excess fuel leading to reduced auto-ignition delay. The observations indicate that traditional over-fuelling is a highly unsuitable method of knock suppression in modern downsized spark ignition engines, even without considering the other detrimental effects of rich combustion on thermal efficiency and tailpipe pollutant emissions. However, some caution is recommended given the simple nature of the fuels adopted and future work will consider the effects of a wider suite of fuels. 


\section{REFERENCES:}

[1] Cairns A, Stansfield P, Fraser N, Blaxill H, Gold M, Rogerson J, et al. A Study of GasolineAlcohol Blended Fuels in an Advanced Turbocharged DISI Engine. SAE Int J Fuels Lubr 2009;2:41-57. doi:10.4271/2009-01-0138.

[2] Gröger O, Gasteiger HA, Suchsland J-P. Review-Electromobility: Batteries or Fuel Cells? J Electrochem Soc 2015;162:A2605-22. doi:10.1149/2.0211514jes.

[3] Moxey BG, Cairns A, Zhao H. A Study of Turbulent Flame Development with Ethanol Fuels in an Optical Spark Ignition Engine, 2014. doi:10.4271/2014-01-2622.

[4] Cairns A, Zhao H, Todd A, Aleiferis P. A study of mechanical variable valve operation with gasoline-alcohol fuels in a spark ignition engine. Fuel 2013;106:802-13. doi:10.1016/j.fuel.2012.10.041.

[5] Turner JWG, Pearson RJ, Dekker E, Iosefa B, Johansson K, ac Bergström K. Extending the role of alcohols as transport fuels using iso-stoichiometric ternary blends of gasoline, ethanol and methanol. Appl Energy 2013;102:72-86. doi:10.1016/j.apenergy.2012.07.044.

[6] Lumsden G, OudeNijeweme D, Fraser N, Blaxill H. Development of a Turbocharged Direct Injection Downsizing Demonstrator Engine. SAE Int J Engines 2009;2:1420-32. doi:10.4271/2009-01-1503.

[7] Ricardo HR. Paraffin as Fuel. Automob Eng 1919:2-5.

[8] Zhen X, Wang Y, Xu S, Zhu Y, Tao C, Xu T, et al. The engine knock analysis - An overview. Appl Energy 2012;92:628-36. doi:10.1016/j.apenergy.2011.11.079.

[9] Bozza F, De Bellis V, Teodosio L. Potentials of cooled EGR and water injection for knock resistance and fuel consumption improvements of gasoline engines. Appl Energy 2016;169:112-25. doi:10.1016/j.apenergy.2016.01.129.

[10] De Bellis V. Performance optimization of a spark-ignition turbocharged VVA engine under 
knock limited operation. Appl Energy 2016;164:162-74.

doi:10.1016/j.apenergy.2015.11.097.

[11] Dingle SF, Cairns A, Zhao H, Williams J, Williams O, Ali R. Lubricant Induced Pre-Ignition in an Optical SI Engine, 2014. doi:10.4271/2014-01-1222.

[12] Rassweiler GM, Withrow L. Motion Pictures of Engine Flames Correlated with Pressure Cards. 1938. doi:10.4271/380139.

[13] Cairns A, Fraser N, Blaxill H. Pre Versus Post Compressor Supply of Cooled EGR for Full Load Fuel Economy in Turbocharged Gasoline Engines. SAE Tech. Pap., SAE International; 2008. doi:10.4271/2008-01-0425.

[14] Knop V, Essayem E. Comparison of PFI and DI Operation in a Downsized Gasoline Engine. SAE Int J Engines 2013;6:941-52. doi:10.4271/2013-01-1103.

[15] Wang Z, Liu H, Song T, Xu Y, Wang J-X, Li D-S, et al. Investigation on Pre-ignition and Super-Knock in Highly Boosted Gasoline Direct Injection Engines. SAE Tech. Pap., SAE International; 2014. doi:10.4271/2014-01-1212.

[16] Stapf KG, Reis B. "Simulation of Auto-Ignition Behaviour for Varying Gasoline Engine Operating Conditions”, Proceedings of the 2nd Conference on Engine Processes: July 2--3, 2015, Berlin, Germany. Universit\{ä\}tsverlag der TU Berlin; 2015.

[17] Fieweger K, Blumenthal R, Adomeit G. Self-ignition of S.I. engine model fuels: A shock tube investigation at high pressure. Combust Flame 1997;109:599-619. doi:10.1016/S00102180(97)00049-7.

[18] Ciezki HK, Adomeit G. Shock-tube investigation of self-ignition of n-heptane-air mixtures under engine relevant conditions. Combust Flame 1993;93:421-33. doi:10.1016/00102180(93)90142-P.

[19] Pan J, Sheppard CGW, Tindall A, Berzins M, Pennington S V., Ware JM. End Gas Inhomogeneity, Autoignition and Knock, 1998. doi:10.4271/982616. 
[20] König G, Maly RR, Bradley D, Lau a KC, Sheppard CGW. Role of Exothermic Centres on Knock Initiation and Knock Damage 1990:902136. doi:10.4271/902136.

[21] Kalghatgi GT, Bradley D. Pre-ignition and "super-knock" in turbo-charged spark-ignition engines. Int J Engine Res 2012;13:399-414. doi:10.1177/1468087411431890.

[22] Male T. The third symposium on combustion, flame and explosion phenomena, n.d.

[23] Pan J, Shu G, Wei H. Research on in-cylinder pressure oscillation characteristic during knocking combustion in spark-ignition engine. Fuel 2014;120:150-7. doi:10.1016/j.fuel.2013.11.054.

[24] Brecq G, Le Corre O. Modeling of in-cylinder pressure oscillations under knocking conditions: introduction to pressure envelope curve. SAE 2005 World Congr. Exhib. Pap., 2005, p. 1126.

[25] Konig G, Sheppard CGW. End Gas Autoignition and Knock in a Spark Ignition Engine. SAE Tech. Pap., SAE International; 1990. doi:10.4271/902135.

[26] Katsumata M, Morikawa K, Tanabe M. Behavior of Shock Wave and Pressure Wave of SI Knocking with Super Rapid Compression Machine. SAE Tech. Pap., SAE International; 2011. doi:10.4271/2011-01-1875.

[27] Kawahara N, Tomita E. Visualization of auto-ignition and pressure wave during knocking in a hydrogen spark-ignition engine. Int J Hydrogen Energy 2009;34:3156-63. doi:10.1016/j.ijhydene.2009.01.091.

\section{ACRONYMS}

aTDC: $\quad$ after Top Dead Centre

$\begin{array}{ll}\text { AFR: } & \text { Air-to-Fuel Ratio } \\ \text { bTDC: } & \text { before Top Dead Centre }\end{array}$


BMEP: $\quad$ Brake Mean Effective Pressure

BSFC: $\quad$ Brake Specific Fuel Consumption

CA: $\quad$ Crank Angle

CCV: $\quad$ Cycle-by-Cycle Variation

COV: $\quad$ Coefficient of Variation

DI: Direct Injection

EU: $\quad$ European Union

ID: Injection Duration

IDS: $\quad$ Injection Duration Sweep

IMEP: $\quad$ Net Indicated Mean Effective Pressure

MFB: $\quad$ Mass Fraction Burned

NEDC: $\quad$ New European Drive Cycle

PFI: $\quad$ Port Fuel Injection

RON: $\quad$ Research Octane Number

SOI: $\quad$ Start of Injection

SOIS: $\quad$ Start of Injection Sweep

SI: $\quad$ Spark Ignition

TDC: $\quad$ Top Dead Centre

VVT: $\quad$ Variable Valve Timing

WOT: $\quad$ Wide Open Throttle 


\section{APPENDICES:}

\section{APPENDIX A: FUEL PROPERTIES}

\begin{tabular}{|l|l|l|}
\hline Property & Iso-Octane & n-Heptane \\
\hline Chemical Formula & C8H18 & C7H16 \\
\hline Boiling point at $\left.1 \mathrm{~atm}^{\circ}{ }^{\circ} \mathrm{c}\right)$ & 99.2 & 98.4 \\
\hline Enthalpy of vaporisation at $298.15 \mathrm{~K}$ & 35.14 & 36.63 \\
\hline MJ/Kmol) & & \\
\hline Density at $25^{\circ} \mathrm{C}\left(\mathrm{Kg} / \mathrm{m}^{3}\right)$ & 690.4 & 681.5 \\
\hline Latent Heat of Vaporisation(kJ/kg) & 308 & 318 \\
\hline Reid Vapour Pressure (bar) & & \\
\hline Oxygen Content by Weight $(\%)$ & 0.52 & 0.12 \\
\hline Volumetric Energy Content $(\mathrm{MJ} / \mathrm{l})$ & 30.6 & 30.48 \\
\hline RON (MON) & 0 & 0 \\
\hline
\end{tabular}

Table A1: Primary reference fuel properties 


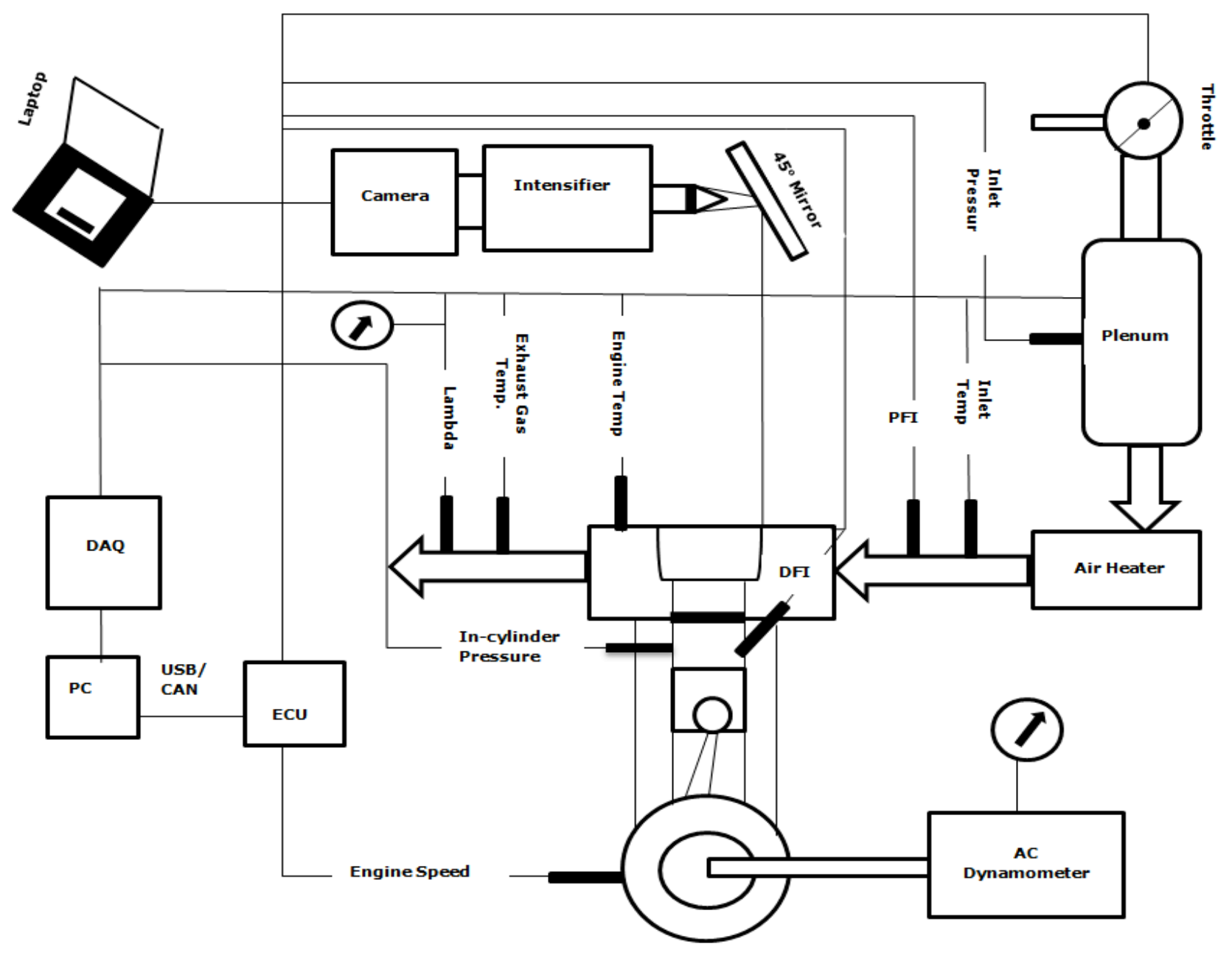

Figure B1: Schematic of experimental engine control, image capture $\&$ data acquisition systems 